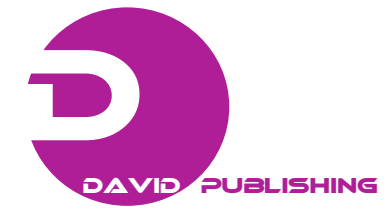

\title{
New Line of Drinks Based on Grape Products
}

\author{
Zaira Shapatava, Kukuri Dzeria, Lali Goginava and Zviad Bobokashvili \\ Institute of Horticulture, Viticulture and Oenology of the Agricultural University of Georgia, Tbilisi 0159, Georgia
}

Received: October 8, 2011 / Published: February 20, 2012.

\begin{abstract}
Fruit processing is the appropriative way to augment fruit intake. The present paper shows production technology, which is based on the characteristics of selected raw materials and does not use sugar (saccharose). The objective of the present paper is to produce healthful and disease preventive beverages based on "Saperavi" red wine and bilberries, using grape juice concentrate and stevioside, a natural sweetener, instead of saccharose. The technology is based on the removal of alcohol at a low temperature and low pressure. In these conditions about $50 \%$ of moisture is evaporated. The extract is then diluted with $0.25 \%$ of stevioside liquid and the ratio is 1:1. The working name is "Saperavi-S". Bilberry juice is added to this beverage at the ratio of $1: 1$ in order to enrich it with biologically active substances. The working name of this beverage is "Marnidan". The products have high contents of phenolic compounds, mainly-anthocyanins. The main idea of technology uses bilberry juice with grape juice concentrate. Bilberries have quite high antioxidant activity, amounting to 55\% against 1,1-Diphenyl-2-picrylhydrazyl. It is the first time we have produced a beverage based on dealcoholized red wine, stevioside and bilberry juice. This beverage is of special importance in terms of its disease-preventive qualities, including prevention of diabetes, one of the most widespread chronic diseases.
\end{abstract}

Key words: Antioxidants, anthocyanins, flavanols, non-alcoholic wine, beverage, bilberry, steviosid.

\section{Introduction}

Profound and important changes have occurred lately in human mentality regarding nutrition physiology. New tendencies have developed initiating reformation of nutrition landscape. They are based on the modern medical researches showing curative and preventive qualities of fruits depending on the contents of bioactive substances [1-3]. The focus is on the compliance of the products with medical and biological requirements.

Free radicals are formed in the human body under the influence of negative factors. These are molecules with unpaired electrons, which take the lacking electrons from proteins, fats, DNA, damaging cells and contributing to the development of cancer, arthritis, diabetes, cardiovascular diseases, immune system weakening, etc. [4-9].

Fruits contain substances inhibiting or reducing oxidation. These are mainly phenolic compounds,

Corresponding author: Zaira Shapatava, Ph.D., research field: fruit processing-functional products. E-mail: zairashapatava@mail.ru. including anthocyanins, which show the highest antioxidant activity $[3,10,11]$.

Fruits vary by their contents of antioxidants and other important phytochemicals. Consumption of fresh fruits is limited to their ripening season. Rational use of fruits can be achieved through selection and development of the appropriate fruit processing technologies. Another important issue is reducing the saccharose contents in the product based on the World Health Organization data (WHO, 2003).

Saccharose is believed to be an efficient immunodepressant raising insulin and glucose levels, contributing to the development of atherosclerosis, obesity, etc.. A total of $>50$ negative factors have been identified [12, 13]. However, sugar is a source of energy as adenosine triphosphate is synthesized during its oxidation. It has been established that the lack of sugar for 2.0-2.5 weeks significantly reduces the glucose level in the blood causing hypoglycaemia. Saccharose can be replaced with natural glucose and fructose. The other phytochemicals slow down the 
absorption of glucose. As for fructose, its metabolism is either insulin independent or requires a very small amount of insulin. Products can be sweetened with sweeteners which do not increase the calorie content.

In this regard stevioside is especially noteworthy. It is a glycoside extracted from Stevia leaves (Stevia rebaudiana Bertan). It does not only form gustatory qualities of a product, but also regulates blood glucose level, has anticancerogenic, antihyperglycemic and insulinotropic effects [14-16].

Nowadays bilberries are acknowledged to be one of the main products in healthcare. Bilberries facilitate strengthening of vascular walls, normalization of capillary permeability, reduction of the risks of cardiovascular diseases, cancer and thrombus development, sight improvement. Bilberries are included in the pilots' and astronauts' diet due to their unique quality to preserve eye sight. The high contents of phenolic compounds, mainly anthocyanins, account for the antioxidant qualities of bilberries [17, 18].

The great interest in grapes is associated with winemaking. Wine deserves special attention not only due to its excellent flavour and aroma, but also high contents of bioactive substances. Red wines have the best protective qualities against free radicals [19-22]. The antioxidant activity of wine depends mainly on the contents of anthocyanins. However, due to the contents of alcohol wine is not recommended to the patients with chronic diseases, especially diabetes, which is so widespread worldwide that it is often called a "non-infectious epidemic disease of the 21st century". In this regard the current trend is production of non-alcoholic and low-alcoholic beverages (see the materials of the $33^{\text {rd }}$ World Conference of Vine and Wine) and products with sweeteners. Sweeteners have higher sweetness level in fewer concentrations than sugar.

Glucose and fructose are important not only in wine production. Grape juice concentrate can be used instead of saccharose in fruit processing. This is particularly topical taking into account the recent trends regarding saccharose consumption.
The objective of the present paper is to produce healthful and preventive beverages based on "Saperavi" red wine and bilberries, using grape juice concentrate and stevioside, a natural sweetener.

\section{Materials and Methods}

The beverages based on dry red wine (alcohol content of $13^{\circ}$ ) were produced in the experimental wine cellar of the Institute of Horticulture, Viticulture and Oenology, using Saperavi, wild bilberries (Vaccinium myrtillus L.), Rkatsiteli grape juice concentrate $\left(65^{\circ}\right.$ Brix) and stevioside.

The production technology involves removal of alcohol from the wine while preserving anthocyanins and other bioactive substances.

The technology consists of the following processes: removal of alcohol at $40{ }^{\circ} \mathrm{C}-50{ }^{\circ} \mathrm{C}$ in the vacuum conditions. The results are achieved when $\approx 50 \%$ of moisture is evaporated. The extract is diluted with $0.2 \%-0.25 \%$ stevioside solution at the ratio of $1: 1$.

The working name of the beverage is Saperavi-S. It can be used for the production of nectars and blending. The beverage should be enriched and balanced with biologically active substances.

In this regard bilberries are especially noteworthy. Another beverage is made by mixing bilberry juice and "Saperavi-S" at the ratio of 1:1. The working name of this beverage is "Marnidan".

Bilberry juice can be produced by adding grape juice concentrate at the ratio of $4: 1$ or $5: 1$ depending on the contents of sugar and acid in the bilberries. This method allows to preserving the biologically active substances and ensuring high organoleptic qualities of the product. This beverage is recommended for prevention of a wide rage of chronic diseases.

The total concentration of anthocyanins in the aforementioned products was measured with photoelectric calorimeter at a wave length of $530 \mathrm{~nm}$, dry solids were measured with a refractometer, the titratable acidity and $\mathrm{pH}$-with a $\mathrm{pH}$ meter, anthocyanins, flavonols, phenolic carbon acids-with highly-effective 
Varian Prostar liquid chromatograph. Concentration of mineral elements was measured with atomic absorption spectrometer (AANALIST 400).

\section{Results and Discussion}

The conducted research is innovative in terms of wine use optimization. The produced beverages contain no alcohol, but retain all important bioactive substances, which expands and reinforces its function in nutrition physiology.

The antioxidant activity of the red wine mostly depends on the contents of anthocyanins. Therefore the main focus is on their stability during the technological process. $>15$ anthocyanins have been identified in wine. Most of them are glycosides of anthocyanidins, like malvidin and peonidin. There is also a small amount of anthocyanins derived from cyanidin.

The anthocyanins content in the wine totals to 535 $\mathrm{mg} / \mathrm{L}$. Theoretically, when $50 \%$ of moisture is evaporated, the concentration should become 1,070 $\mathrm{mg} / \mathrm{L}$, but the analysis shows $981 \mathrm{mg} / \mathrm{L}$. The removal of alcohol does not reduce the content of anthocyanins significantly. The reduction is only $8.3 \%$.

After adding $0.20 \%$ stevioside solution to the non-alcoholic concentrate the anthocyanins content becomes $486 \mathrm{mg} / \mathrm{L}$. Thus, the difference is only $9 \%$, which is consistent with the loss during the technological process (Fig. 1).

Bilberries anthocyanins are derived from 5 anthocyanidins, namely cyanidin, delphinidin, malvidin, petunidin and peonidin. They have quite high antioxidant capacity and the total content of anthocyanins is $3,200 \mathrm{mg} / \mathrm{L}$.

In view of the above the use of bilberry juice in "Marnidan" will increase both the contents and quality of anthocyanins. In "Saperavi" there is a relatively small amount of anthocyanins derived from cyanidin. As a result various free radicals can be inhibited.

The total content of anthocyanins in "Saperavi-S" is similar to that in wine. When bilberry juice is added the content of anthocyanins is increased 3.5 times.

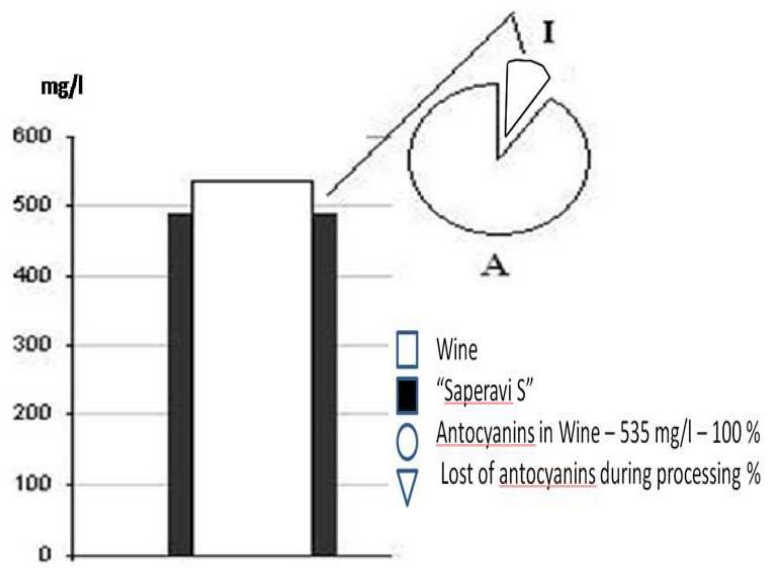

Fig. 1 The total content of anthocyanins in wine and “Saperavi-S", mg/L.

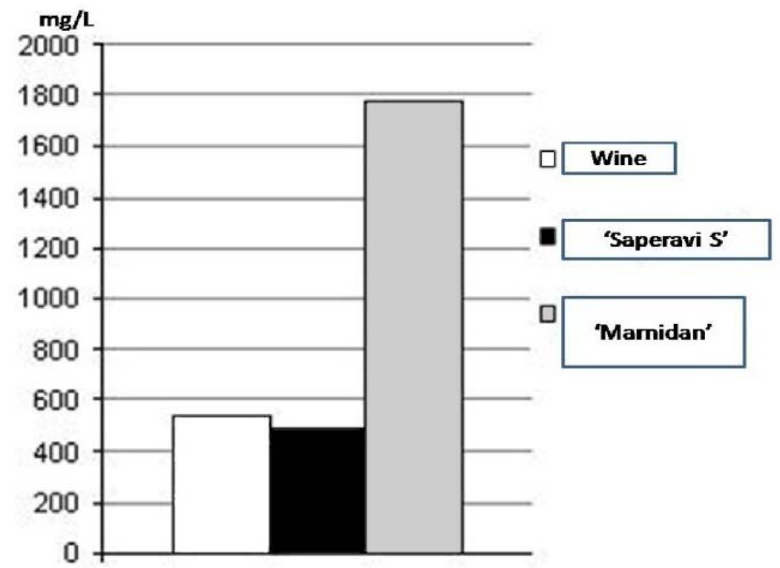

Fig. 2 The total content of anthocyanins in wine and in the produced beverages, $\mathrm{mg} / \mathrm{L}$.

Another product is bilberry juice sweetened with grape juice concentrate instead of sugar. In addition to anthocyanins this juice also contains flavanols and phenolic carboxylic acids. The chromatograph recorded more than 10 peaks, out of which several have been identified. Some of the substances found in comparatively large proportions are + catechin, epicatechin, chlorogenic acid, p-coumaric acid and sinapic acid (Table 1).

Bilberry juice also has high contents of mineral elements, like $\mathrm{K}, \mathrm{Ca}, \mathrm{Mg}, \mathrm{Na}$ and $\mathrm{Zn}$, which are essential for human health. Besides $\mathrm{Zn}$ is an antioxidant.

The antioxidant capacity of bilberry juice is quite high. Its antioxidant activity measured using 1,1-Diphenyl-2-picrylhydrazyl (DPPH) is $55 \%$ and Trolox equivalent of antioxidant capacity is $56.5 \%$. 
Table 1 Contents of Flavanols, phenolic carboxylic acids and mineral elements in bilberry juice, $\mathrm{mg} / \mathrm{L}$.

\begin{tabular}{lclr}
\hline Substance & Content & Mineral Element & Content \\
\hline$(+)$ catechin & 43.04 & $\mathrm{~K}$ & $1,052.0$ \\
(-) epicatechin & 18.28 & $\mathrm{Ca}$ & 127.0 \\
Chlorogenic acid & 28.30 & $\mathrm{Mg}$ & 74.0 \\
Caffeic acid & 3.40 & $\mathrm{Zn}$ & 1.6 \\
P-coumaric acid & 12.9 & $\mathrm{Na}$ & 21.0 \\
Sinapic acid & 9.49 & & \\
Vanillin & 4.33 & & \\
\hline
\end{tabular}

The aforementioned juice can also be used as one of the components in fruit processing technology.

The interest in non-alcoholic wine has been increasing recently. Its production started as early as 100 years ago, at the beginning of the $20^{\text {th }}$ century. Doctor Carl Jung was the first to obtain a patent on it in Germany in 1908 [23].

Non-alcoholic wines have been enjoying increasing popularity lately due to their bioactive qualities. They are produced in France, Germany, Italy, Spain, etc.. In this regard the Californian company, ARIEL deserves a special attention. It produces a wide variety of both white and red non-alcoholic wines, including Cabernet Sauvignon, Merlot, White Zinfandel, Chardonnay and so on [24].

It worthy of note that dealcoholization does not affect original wine qualities. L. Liguori et al. [25] showed that the wine fully retains its phenolics. Moreover, dealcoholization of red wine causes an increase in the antioxidant activity of its anthocyanins [26].

New beverages were produced based on the aforementioned data. The production technology improves the wine qualities. The selected grape variety, Saperavi, is characterized by dark coloured skin and pulp and notably high contents of anthocyanins. Stevioside imparts a sweet and pleasant flavour to the wine and helps prevent diabetes and other chronic diseases, while the bilberry juice increases its antioxidant activity.

The flaws of dealcoholized wine beverages produced in Georgia are as follows: "Gvinisa" has high acidity; production technology of Armazi includes adding of sugar (saccharose) after dealcoholization at the ratio of $7 \mathrm{~g} / 100 \mathrm{~mL}$, which diminishes its disease preventive qualities [27].

The research in this area continues to improve the technology and ensure proper use of the new products.

\section{Conclusion}

Non-alcoholic concentrate of red wine with stevioside and bilberry juice can be used for a new line of products attracting new customers, like diabetes patients. The use of bilberry juice increases the anthocyanins content 3.5 times contributing to the inhibition of free radicals. Bilberry juice has a wide range of functions due to its phytochemical qualities and sugar metabolism is possible with a low level of insulin.

\section{References}

[1] H. Wang, G. Cao, R.L. Prior, Total antioxidant capacity of fruits, J. Agric. Food Chem. 44 (1996) 701-705.

[2] M.P. Kähkönen, A.I. Hopla, I.M. Heinonen, Berry phenolics and their antioxidant activity, J. Agric. Food Chem. 49 (2001) 4076-4082.

[3] I.M. Heinonen, A.S. Meyer, Antioxidants in fruit, berries and Vegetables, Fruit and Vgetable Processing, Woodhead Publising Limited, Cambridge England, 2002, p. 388.

[4] K.A. Steinmetz, J.D. Pottr, Vegetables, fruit and cancer prevention: A review, J. Am. Diet Assoc. 96 (1996) 1027-1037.

[5] K. Bagchi, S. Puri, Free radicals and antioxidants in health and disease, Eastern Mediterranean Health Journal 4 (1998) 350-360.

[6] D. Burdulis, L. Ivanauskas, V. Dirse, S. Kazlauskas, A. Razukas, Study of diversity of anthocyanins composition in bilberry (Vaccinium Myltirus L.) fruits, Medicina (Kaunas) 43 (2007) 971-977.

[7] W. Kalt, C.F. Forney, A. Martin, R.I. Prior, Antioxidant capacity, vitamin $\mathrm{C}$, phenolics and anthocyanins after fresh storage of small fruits, Agric. Food Chem. 47 (1999) 4638-4644.

[8] E.S. Ford, A.H. Mokdad, Fruit and vegetable consumption and diabetes mellitus incidence among U.S. adults, Prev. Med. 32 (2001) 33-39.

[9] S. Southon, R. Faulks, Health Benefits of Increased Fruit and Vegetable Coosumption, Fruit and Vegetable Processing, Woodhead Publishing Limited, Cambridge England, 2002, p. 388. 
[10] C.A. Rice-Evans, N.J. Miller, G. Paganga, Structure-antioxidant activity relationships of flavonoids and phenolic acicis, Free Radic Boil Med. 20 (1996) 933-956.

[11] M.N. Clifford, Anthocyanins, nature, occurrence and dietary burden, J. Sci. Food Agri. 80 (2000) 1063-1072.

[12] The alternative-doctor nutrition section, $\mathrm{http} / / / \mathrm{www}$.alternative-doctor.com/nutrition/sugar.htm.

[13] The side effects of sugar by Edward Howell, http://www.earthincommon.com/rethink_01-article.html.

[14] P.B. Jeppesen, S. Gregersen, K.K. Ahstrup, K. Hermansen, Stevioside induces antihyperglicaemic, insulinotropic and glucagonstatic effects in vivo: Studies in the diabethic Goto-Kakizaki (GK) rats, Phytomedicine 9 (2002) 9-14.

[15] N.C. Rodionova, L.C. Glagoleva, K.K. Polyanski, Prospects of using stevia to decrease calorie content of milk deserts, Food Industry 11 (1998) 36.

[16] V.I. Lisitsin, I.P. Kovalev, Stevia-source of the nation's health and longevity, Food Industry 5 (2000) 38.

[17] G. Beccapo, M. Mellano, R.G. Botta, V. Chiabrando, G. Bounous. Phenolic and anthocyanin content and antioxidant activity in fruits of bilberry (Vaccinium Mirtillus L.) and of highbush blueberry (Vaccinium Corymbosum L.) cultivars in north-western Italy, J. Acta. Hort. 715 (2006) 553-558.

[18] I.M. Heinonen, A.S. Meyer, E.N. Frankel, Antioxidant activity of berry phenolics on human low-density lipoprotein and liposome oxidation, J. Agric Food Chem. 46 (1998) 4107-4112.
[19] M. Micallef, L. Lexis, P. Lewandowski, Red wine consumption increases antioxidant status and decreases oxidative stress in the circulation of both young and old humans, Nutrition Journal 6 (2007) 27.

[20] A.S. Meyer, O.S. Yi, D.A. Pearson, A.L. Waterhouse, E.N. Frankel, Inhibition of human low density lopoprotein oxidation in relation to composition of phenolic antioxidants in grapes (Vitis Vinifera), Journal Agric. Food Chem. 45 (1997) 1638-1643.

[21] J.A. Vinson, B.A. Honts, Phenol antioxidant index: Comparative antioxidant effectiveness of red and white wines, J. Agric. Food Chem. 43 (1995) 401-403.

[22] F. Hesford, K. Schneider, Anthocyane: Die natülichen Farbstoffe des Weines, Obst-Weinbau 22 (1997) 550-561.

[23] The history of Carl Jung wines, http://www.carljungwines.com/legend.htm.

[24] Ariel non alcoholic wines, http://www.clearmind.com.au/ariel.html.

[25] L. Liguori, G. Attanasion, D. Albanese, M. Di Matteo, Aglianico wine dealcoholization tests, in: $20^{\text {th }}$ European Sumposium on Computer Aided Process Engineering, ESCAPE 20, 2010.

[26] M. Serafini, G. Maiani, A. Ferro-Luzzi, Alcohol-free red-wine enhances plazma antioxidant capacity in humans, Journal Nutrition 6 (1998) 1003-1007.

[27] M.I. Zautashvili, B.I. Tchumburidze, V.A. Aladashvili, Alcohol Free Wine and Its Application, Publishing House, Sakartvelo, 1984. 